\title{
Klasterisasi Manajemen Pengolahan Limbah Sapi Bali pada Simantri di Kabupaten Badung
}

\author{
(THE CLUSTERING OF BALI CATTLES WASTE PROCESSING MANAGEMENT AT \\ SIMANTRI IN BADUNG REGENCY)
}

\author{
Dewa Made Dwi Parwata1*, I Putu Sampurna², I Made Sukada ${ }^{3}$, \\ Kadek Karang Agustina ${ }^{3}$
}

\author{
${ }^{1}$ Praktisi Dokter Hewan di Br. Penginyahan, Puhu, Payangan, Gianyar, Bali. \\ ${ }^{2}$ Laboratorium Biostatistik, Fakultas Kedokteran Hewan, Universitas Udayana. \\ ${ }^{3}$ Laboratorium Kesehatan Masyarakat Veteriner, Fakultas Kedokteran Hewan, \\ Universitas Udayana.*Email: dewaparwata08@gmail.com
}

\begin{abstract}
ABSTRAK
Penelitian klasterisasi manajemen pengolahan limbah sapi bali pada sistem pertanian terintegrasi (simantri) di Kabupaten Badung, bertujuan untuk mengetahui komponen-komponen pengolahan limbah sapi bali yang belum dilakukan secara intensif dan untuk mengetahui Gapoktan mana yang belum melakukan sitem pengolahan limbah sapi bali secara intensif pada Simantri di Kabupaten Badung.Pengambilan sampel dilakukan secara teknik sampling jenuh, kemudian data yang diperoleh dianalisis menggunakan Hierarchical cluster dengan Plot dendogram clusterdengan variabel penciri intensif, semi intensif, dan ekstensif. Hasil dari penelitian ini menunjukan bahwa komponen manajemen pengolahan limbah sebagian besar dilakukan secara intensif yaitu perlakuan limbah oleh peternak, pengolahan limbah padat, pengolahan limbah cair, teknologi pengolahan limbah padat, teknologi pengolahan limbah cair, alat pengolahan limbah padat, alat pengolahan limbah cair, pembinaan pengolahan limbah, pembinaan pemasaran hasil limbah.Sedangkan komponen manajemen perkandangan yang masih diterapkan secara semi intensif yaitu hasil pengolahan limbah padat, hasil pengolahan limbah cair, keuntungan pengolahan limbah padat dan keuntungan pengolahan limbah cair. Kesimpulan penelitian ini yaitu dari 50 Gapoktan yang ada di Simantri di Kabupaten Badung, 42 Gapoktan sudah melaksanakan pengolahan limbah secara intensif, 6 Gapoktan yang melaksanakan pengolahan limbah secara semi intensif dan 2 Gapoktan yang tidak melaksanakan pengolahan limbah atau masuk ke kategori ekstensif yang perlu mendapatkan penyuluhan dari pemerintah agar semuanya menjadi intensif.
\end{abstract}

Kata kunci: Simantri; manajemen pengolahan limbah; cluster; intensif

\begin{abstract}
These research aims were to find out the components of bali cattle waste processing that have not been intensively carried out and to find out which Gapoktan has not carried out an intensive bali cattle processing system in Simantri Badung Regency. Sampling was carried out by saturated sampling technique, then the data obtained were analyzed by Hierarchical cluster with dendrogram cluster plot with intensive, semi-intensive, and extensive identifying variables. The results of this study indicate that the components of waste management are mostly carried out intensively, namely waste treatment by farmers, solid waste treatment, wastewater treatment, solid waste treatment technology, liquid waste treatment technology, solid waste treatment equipment, liquid waste treatment equipment, coaching sewage treatment, marketing of waste products coaching. Meanwhile, the housing management component that is still applied semi-intensively namely the result of processing solid waste, the results of processing wastewater, the advantages of processing solid waste and the benefits of wastewater treatment. The conclusion of this study is that of the 50 Gapoktan in Simantri in Badung Regency, 42 Gapoktan have carried out intensive waste treatment, 6 Gapoktan who carry out semi-intensive waste treatment and 2 Gapoktan who do not carry out waste treatment or enter the extensive category that need to get counseling from the government so that everything becomes intensive.
\end{abstract}

Keywords: Simantri; waste management; cluster management; intensive. 


\section{PENDAHULUAN}

Sistem Pertanian Terintegrasi atau lebih dikenal dengan Simantri telah menjadi model pembangunan pertanian daerah Provinsi Bali dan tersebar pada seluruh kabupaten dan satu kota di Provinsi Bali (Biro Humas Provinsi Bali, 2013). Ide program Simantri dimulai tahun 2008 dan baru terealisasikan pada tahun 2009 dengan salah satu syarat adanya Gapoktan yang mau dan mampu melaksanakan program integrasi (Bhuanaputra dan Yasa, 2017). Gapoktan merupakan gabungan dari beberapa kelompok tani yang melakukan usaha agribisnis dengan prinsip kebersamaan untuk mencapai peningkatan produksi dan pendapatan usahatani bagi anggota (Warsana, 2009).

Kabupaten Badung salah satu kabupaten yang mengikuti program Simantri, dengan total Simantri aktif yang terealisasikan mulai tahun 2009-2016 mencapai 50 Simantri dan tersebar pada tiga Kecamatan Mengwi, Kecamatan Abiansemal, dan Kecamatan Petang. (Dinas Tanaman Pangan, Holtikultura, dan Perkebunan Provinsi Bali, 2016). Sudita et al., (2015) menyatakan satu kelompok Simantri terdiri atas 20 orang anggota Kelompok Tani (Poktan) dengan bantuan dari pemerintah berupa: satu unit kandang koloni, bibit induk sapi bali, fasilitas pengolahan pupuk organik (padat dan cair), pembuatan biogas serta pendampingan.

Sapi bali merupakan salah satu bagian dari sub sistem dalam Simantri. (Dismawan et al., 2014) menyatakan keunggulan sapi bali (Bos sondaicus) dapat beradaptasi pada kondisi lingkungan yang kurang baik, suhu, kelembaban, dan pemanfaatan pakan dengan kualitas rendah (Suwiti et al., 2017). Untuk meningkatkan potensi yang dimiliki sapi bali yaitu melalui manajemen pemeliharaan yang baik. Keberhasilan peternakan sapi bali pada simantri harus disertai dengan manejemen pengolahan limbah yang baik, agar tidak terjadi pencemaran lingkungan akibat penumpukan limbah peternakan (Agustina et al., 2013).
Limbah peternakan meliputi semua kotoran berupa limbah padat, cair, gas ataupun sisa pakan (Soehadji, 1992). Pada simantri para peternak sudah mendapatkan bantuan fasilitas pengolahan pupuk organik dan pembuatan biogas (Sudita et al., 2015), akan tetapi kenyataan dilapangan para peternak masih ada yang belum memanfaatkan fasilitas pengolahan limbah tersebut, bahkan dibiarkan saja dan ada juga yang menjemurnya kemudian dijual. Hal tersebut diakibatkan karena sistem pemeliharaan sapi bali masih secara tradisional dan sebagian besar peternak bergabung dalam Simantri hanya sebagai pekerjaan sambilan (Abutani et al., 2010). Bila peternak mau menerapkan manajemen pengolahan limbah yang baik maka hasil produksi dapat dialokasikan sebagai sumber pendapatan anggota dan untuk pengembangan Simantri (Sanjaya, 2013).

Klasterisasi merupakan pengelompokan komponen-komponen manejemen pengolahan limbah yang diterapkan dalam Simantri dengan tujuan untuk mengetahui tingkat intensitas menejemen pengolahan limbah yang diterapkan. Oleh sebab itu, perlu dilakukan penelitian berupa klasterisasi manejemen pengolahan limbah pada Gapoktan di Simantri Kabupaten Badung untuk tercapainya program Simantri yang sesuai dengan yang diharapkan pemerintah.

\section{METODE PENELITIAN}

\section{Objek Penelitian}

Objek dari penelitian ini yaitu seluruh Simantri yang ada di Gapoktan Kabupaten Badung, yaitu 50 kelompok Simantri yang masih aktif beroperasi sejak tahun 20092016.

\section{Bahan dan Peralatan Penelitian}

Kuesioner dengan daftar pertanyaan mengenai manajemen pengolahan limbah yang meliputi pemanfaatan limbah peternakan sapi, pengolahan limbah padat, pengolahan limbah cair, hasil pengolahan limbah padat, hasil pengolahan limbah cair, keuntungan pengolahan limbah padat, 
keuntungan pengolahan limbah cair, teknologi pengolahan limbah padat, teknologi pengolahan limbah cair, alat yang digunakan untuk pengolahan limbah padat, alat yang digunakan untuk pengolahan limbah cair, pembinaan pemerintah dalam pengolahan limbah, pembinaan pemerintah dalam pemakaian atau pemasaran hasil pengolahan limbah. Dan alat-alat tulis untuk pencatatan data dan kamera untuk dokumentasi saat penelitian.

\section{Rancangan Penelitian}

Penelitian ini merupakan penelitian verifikatif deskriptif kualitatif di lakukan dengan purposive sampling untuk menentukan Kabupaten Badung sebagai salah satu dari delapan Kabupaten di Propinsi Bali. Pengambilan sempel Gapoktan di lakukan secara tenik sampling jenuh.

\section{Variabel Penelitian}

Variabel bebas penelitian yang digunakan berhubungan dengan komponen-komponen manajemen pengolahan limbah yang meliputi pemanfaatan limbah peternakan sapi, pengolahan limbah padat, pengolahan limbah cair, hasil pengolahan limbah padat, hasil pengolahan limbah cair, keuntungan pengolahan limbah padat, keuntungan pengolahan limbah cair, teknologi pengolahan limbah padat, teknologi pengolahan limbah cair, alat yang digunakan untuk pengolahan limbah padat, alat yang digunakan untuk pengolahan limbah cair, pembinaan pemerintah dalam pengolahan limbah, pembinaan pemerintah dalam pemakaian atau pemasaran hasil pengolahan limbah. Variabel terikat penelitian ini adalah intensifikasi manajemen pengolahan limbah yaitu Intensif, Semi Intensif dan Ekstensif.

\section{Cara Pengumpulan Data}

Teknik pengumpulan data dalam penelitian ini yaitu dengan menggunakan kuisioner (angket), wawancara dan pengamatan secara langsung di lapangan.
Data diambil dari 50 Simantri di Gapoktan Kabupaten Badung yang mencakup 3 kecamatan, yaitu Kecamatan Mengwi yang berjumlah 20 Simantri, Kecamatan Abiansemal yang berjumlah 18 Simantri dan Kecamatan Petang yang berjumlah 12 Simantri.

\section{Prosedur Penelitian}

Wawancara dilakukan secara terstruktur, dimana daftar pertanyaan sudah dibuat secara sistematis oleh peneliti. Penyusunan daftar pertanyaan diawali dengan identitas responden, baru masuk ke dalam poin-poin yang sudah tertera pada kuisiner atau angket. Pada penelitian ini, responden yang dipilih bisa dari ketua simantri, ketua gapoktan, petugas pendamping simantri atau anggota simantri yang dirasa mampu untuk menjawab pertanyaan dari peneliti.

Daftar pertanyaan pada kuisiner dibuat dengan bentuk pertanyaan tertutup (close question) yang memberikan kesempatan responden untuk memilih jawaban yang telah peneliti siapkan. Kuisioner akan diberikan kepada responden apabila saat melakukan penelitian peneliti kesulitan untuk menemui atau mewawancarai salah satu penanggung jawab dari kelompok Simantri, sehingga peneliti tidak langsung bertanya jawab dengan responden.

\section{Analisis Data}

Teknik analisis data yang digunakan dalam penelitian ini adalah Hierarchical Cluster, dengan 3 indikator pengukuran penciri yaitu intensif, semi intensif dan ekstensif dengan Plot Dendrogram Cluster berdasarkan variabel komponen manajemen pengolahan limbah dan objek (Simantri). Klasterisasi tersebut terdiri dari baik (Intensif), sedang (Semi Intensif), buruk (Ekstensif) dengan skor masingmasing 1, 2, dan 3. Kemudian dilakukan analisis Claster, dengan variabel penciri intensif, semi intensif dan ekstensif (Sampurna et al., 2017). 


\section{HASIL DAN PEMBAHASAN}

Analisis Hierarchical Cluster dengan variabel penciri intensif, semi intensif, dan ekstensif berdasarkan variabel komponen manajemen pengolahan limbah dari data kuisoner yang diperoleh pada Gapoktan di Simantri Kabupaten Badung sebagian besar dilakukan secara intensif dan ada beberapa yang menerapkan semi intensif, sedangkan untuk penerapan yang ekstensif tidak ada.

Tatalaksana manajemen pengolahan limbah yang dilaksanakan secara semi intensif mencakup hasil pengolahan limbah padat mempunyai kesamaan yang sangat dekat dengan hasil pengolahan limbah cair dan keuntungan pengolahan limbah padat mempunyai kesamaan yang sangat dekat dengan keuntungan pengolahan limbah cair.
Semua Gapoktan yang ada di Simantri Kabupaten Badung seharusnya sudah melaksanakan manajemen pengolahan limbah secara intensif, karena setiap Gapoktan yang ada di Simantri mendapatkan bantuan dari pemerintah berupa fasilitas pengolahan pupuk organik (padat dan cair), pembuatan biogas serta pendampingan (Sudita et al., 2015). Namun pada kenyataannya masih terdapat Gapoktan yang tergolong dalam kategori semi intensif dikarenakan belum semua komponen manajemen pengolahan limbah dilaksanakan sesuai dengan standar dari simantri. Bahkan terdapat Gapoktan yang tergolong pada kategori ekstensif, karena belum memanfaatkan fasilitas bantuan tersebut serta ada juga yang sudah pernah melakukan pengolahan limbah namun tidak melanjutkanya, karena alasan alat pengolahan limbahnya bermasalah.

Tabel 1. Hasil Klasterisasi Tatalaksana Manajemen Pengolahan Limbah pada Gapoktan di Simantri Kabupaten Badung

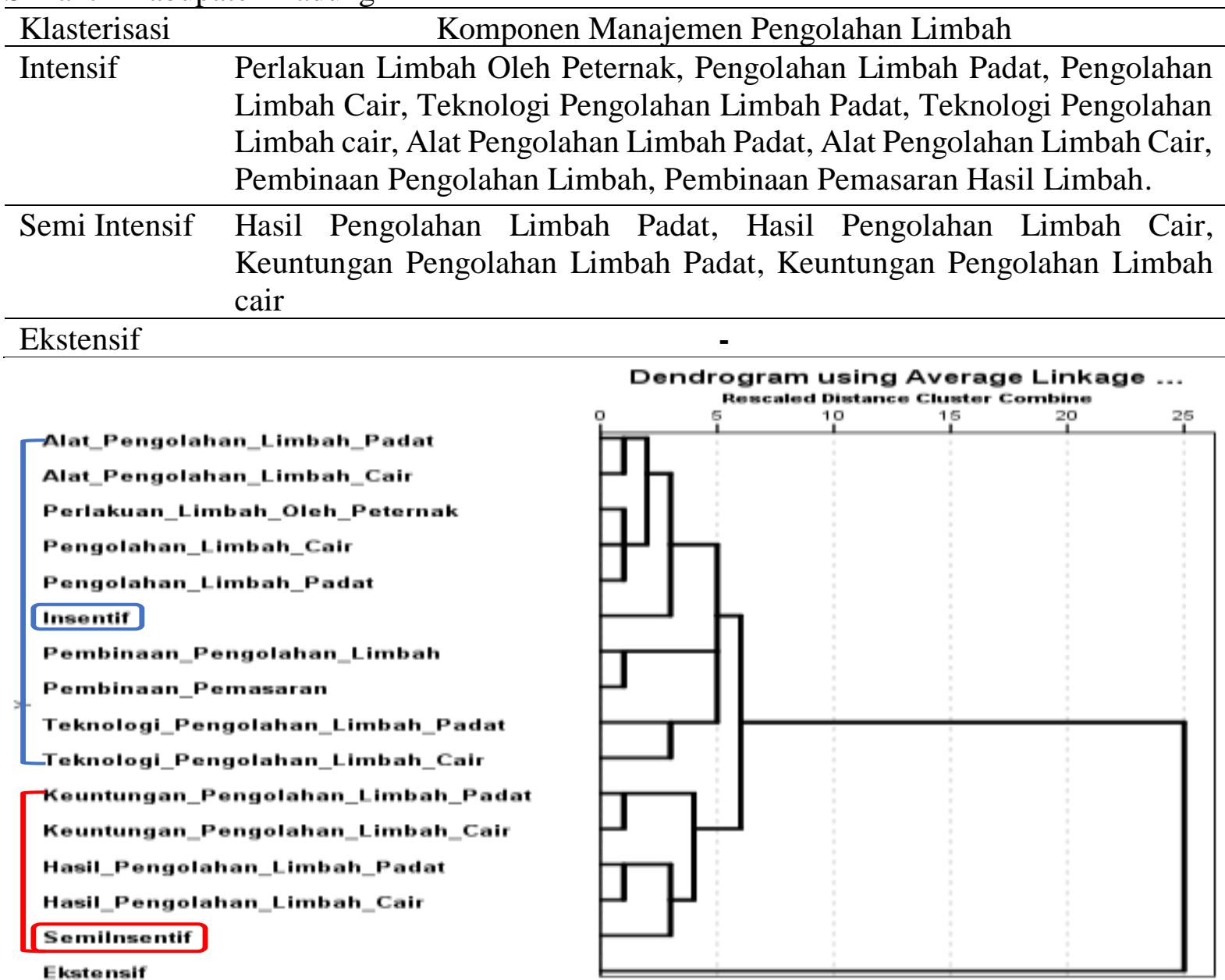

Gambar 1. Dendrogram Manajemen Pengolahan Limbah pada simantri di kabupaten Badung 
Tabel 2. Klasterisasi Gabungan Kelompok Tani di Simantri Kabupaten Badung

\begin{tabular}{ll}
\hline Klasterisasi & \multicolumn{1}{c}{ Gapoktan } \\
\hline Intensif & ManikTirta Rahayu, Gema UnggulSari, Kerta Buana Sari, Sukamaju, KT \\
& Banyu Sari, KTT Panca Urip Mertasari, Werdi Buana, Dharma Pertiwi, \\
& Merta Nadi, Mekar Sari, Poktan Babakan Sari Sangeh, Gata Saga, KTT. Mas \\
& Sari, KTT Sami Polih, KTT Catur Eka Sari, Merta Jati, Taman Wijaya \\
& Kusuma, KTT Buana Mekar, KTT Bala Angon, KT Pula Kerti, Tri Mandala \\
& Sari, Pucak Tedung Sari, KT. Dewi Sari, Merta Bumi Sari 363, Tunjung, KT. \\
& Taman Sari, Getasan, Sari Merta Pertiwi, Tedung Sari, KTT Darma Laksana, \\
& KT. Dharma Karya, Kelompok Merta Jaya 591, Branjungan, Amerta Jaya, \\
& Karang Ayu, Manik Eka Nadi, Puncak Saribon, Wanasari, Gelis Nadi, KT. \\
& Buana Giri, Tani Ternak Rare Angon, Mekar Sari \\
\hline Semi Intensif & KT Gema Makmur Sejati, KT. Karya Mesari, Pertiwi Tani, Sari Lestari, \\
& Cakra Buana, dan KT. Gading Sari \\
\hline Ekstensif & Sri Sedana dan Kerti Buana \\
\hline
\end{tabular}

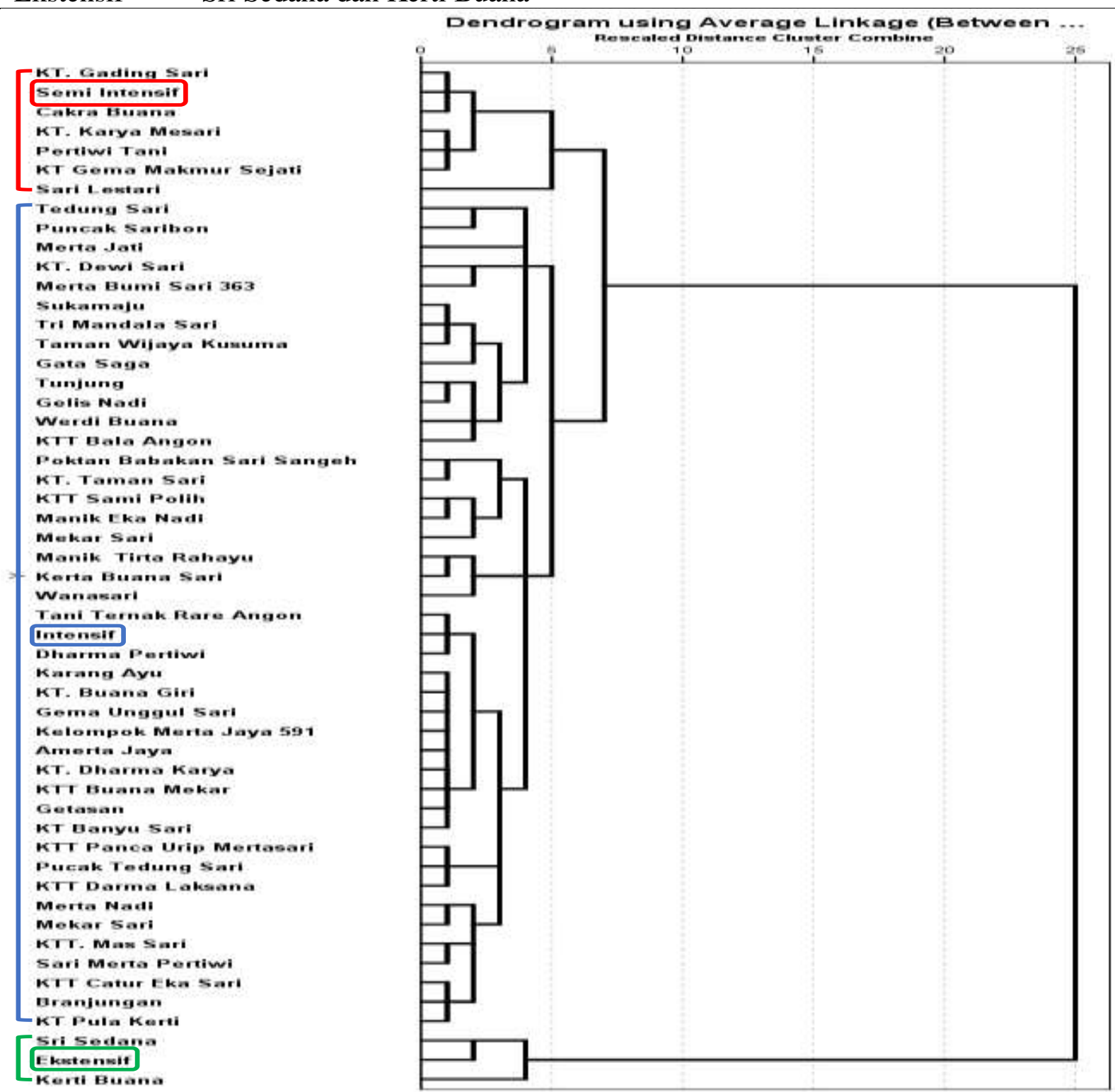

Gambar 2. Dendrogram Gabungan Kelompok Tani di Simantri Kabupaten Badung 
Manajemen pengolahan limbah harus dilakukan secara intensif pada peternakan yang ada dalam Gapoktan demi keberlangsungan Simantri kedepanya, karena selain untuk mencegah pencemaran lingkungan juga berguna sebagai sumber keuntungan bagi peternak (Ginting, 2007). Pada Gapoktan yang ada di Simantri Kabupaten Badung yang masih aktif beroperasi telah melakukan komponen manajemen pengolahan limbah berupa perlakuan limbah oleh peternak, pengolahan limbah padat, pengolahan limbah cair, teknologi pengolahan limbah padat, teknologi pengolahan limbah cair secara intensif.

Limbah padat yang berupa kotoran ternak akan diolah menjadi biogas dan pupuk organik padat dengan menerapkan Teknologi bioregenerator dan pengomposan (Sanjaya et al., 2015). Sementara untuk limbah cair yang berupa air kencing dari ternak akan diolah menjadi pupuk organik cair dengan menggunakan teknologi Bio-urine yang sesuai dengan standar dari pemerintah (Arumingtiyas et al., 2014).

Penerapan manajemen pengolahan secara intensif akan menguntungkan peternak, serta akan memberikan dampak yang positif terhadap lingkungan sekitar peternakan (Agustina et al., 2016). Untuk tercapainya program Simantri yang maksimal perlu ditingkatkan pemahaman anggota tentang tatalaksana manajemen pengolahan limbah yang baik agar dapat mengoptimalkan potensi Gapoktan di Simantri Kabupaten Badung, sehingga dapat membantu mensejahterakan anggota simantri dan mendukung terlaksananya program Simantri.

Dalam melakukan penyuluhan ke simantri yang belum melaksanakan manajemen pengolahan limbah secara intensif, harus dilakukan sesuai dengan hasil yang diperoleh dari analisis menggunakan dendogram claster, dimana pada Gambar 1. Dendogram Klasterisasi Tatalaksana Manajemen Pengolahan Limbah pada Gapoktan di Simantri
Kabupaten Badung, pada gambar tersebut kita bisa melihat manajemen pengolahan limbah yang dilaksanakan secara semi intensif mencakup hasil pengolahan limbah padat mempunyai kesamaan yang sangat dekat dengan hasil pengolahan limbah cair dan keuntungan pengolahan limbah padat mempunyai kesamaan yang sangat dekat dengan keuntungan pengolahan limbah cair, sehingga bisa dilakukan penyuluhan pada komponen tersebut dari melihat kesamaan tatalaksana tersebut dapat diartikan bahwa, bila gapoktan pada simatri melakukan pengolahan limbah padat hanya sekedar diolah maka untuk pengolahan limbah cairnya juga sama sekedar diolah, sehingga bisa dilakukan penyuluhan kedua komponen tersebut secara bersamaan.

Dalam melakukan penyuluhan untuk menentukan simantri yang perlu mendapat penyuluhan tentang manajemen pengolahan limbah bisa dilihat pada Gambar 2. Dendogram Kedekatan Gabungan Kelompok Tani di Simantri Kabupaten Badung, di gambar tersebut kita bisa melihat gapoktan-gapoktan yang memiliki ketatalaksanaan yang sama, bila gapoktan yang memiliki ketatalaksanaan yang sama maka gapoktan tersebut memerlukan penyuluhan tentang komponen pengolahan limbah yang sama dan bisa dilakukan di tempat serta waktu yang bersamaan jika belum intensif.

\section{SIMPULAN}

\section{Simpulan}

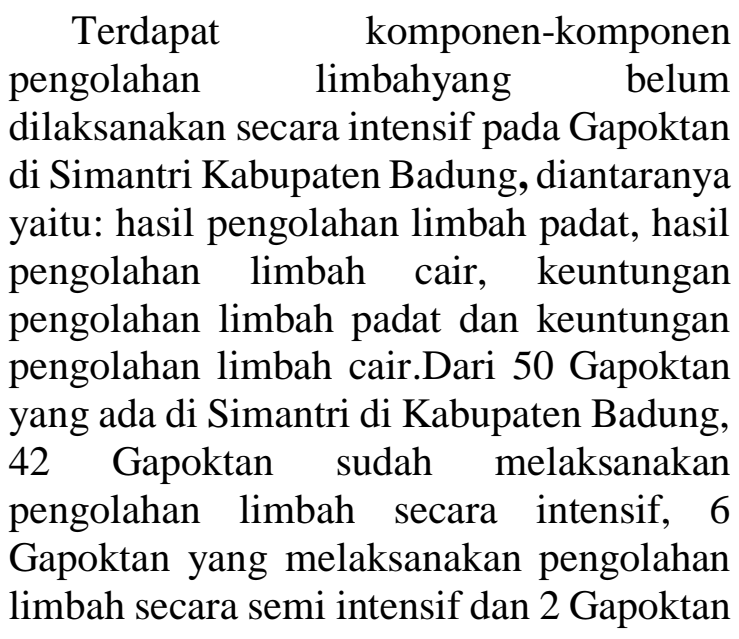


yang tidak melaksanakan pengolahan limbah atau masuk ke kategori ekstensif.

\section{Saran}

Masih perlu dilakukan penyuluhan manajemen pengolahan limbah terhadap Gapoktan yang belum menerapkan manajemen pengolahan limbah secara intensif, agar kedepanya seluruh Gapoktan yang ada di Simantri Kabupaten Badung berjalan sesuai dengan yang diharapkan semuanya melaksanakan manajemen pengolahan limbah secara Intensif.

\section{DAFTAR PUSTAKA}

Abutani SA, Rahim S, Noverma. 2010. Respon Pemberian "Blok Suplemen" Berbasis Bahan Lokal Terhadap Pertambahan Bobot Sapi Bali. J. Sain. Peternakan Indonesia. 5(1): 65-69

Agustina KK, Wirata IW, Dharmayudha AAGO. 2013. Prevalensi toxocara vitulorum pada induk dan anak sapi bali di wilayah Bali Timur. Bul. Vet. Udayana. 5(1): 1-6.

Agustina KK, Wirata IW, Dharmayudha AAGO, Kardena IM, Dharmawan NS. 2016. Increasing farmer income by improved pig management systems. Bul. Vet. Udayana. 8(2): 122-127.

Arumingtiyas WI, Fajriani S, Santosa M. 2014. Pengaruh aplikasi biourine terhadap pertumbuhan dan hasil tanaman padi. J. Prod. Tanaman. 2(8): 620-628.

Biro Humas Sekretaris Daerah Provinsi Bali. 2013. Data Informasi Program Pembangunan Pemerintah Provinsi. Denpasar.

Bhuanaputra KW, Yasa INM. 2017. Efektivitas dan Dampak Program SIMANTRI Terhadap Pendapatan dan Kesempatan Kerja Rumah Tangga Petani di Kecamatan Nusa Penida di Kabupaten Klungkung. E-J. Ekonomi Pembangunan. 6(5): 827-855

Dismawan IWH, Ginantra IK, Suriani NL. 2014. Seleksi Jenis Tumbuhan Pakan Dan Kandungan Nutrien Jenis
Tumbuhan Yang Dimakan Sapi Bali (Bos Sondaicus) Lepas Sapih Di Daerah Bukit Badung Selatan, Kabupaten Badung, Bali. J. Simbiosis. 2(2): 192202.

Dinas Pertanian Tanaman Pangan Pemerintah Provinsi Bali. 2010. Kegiatan Sistem Pertanian Terintegrasi (Simantri) di Provinsi Bali. Denpasar.

Ginting N. 2007. Teknologi Pengolahan Limbahpeternakan. Fakultas Pertanian Universitas Sumatra Utara.

Sampurna IP, Nindhia TS, Sukada IM. 2017. Dendrogram Simulations with Determinatvariable Identifer to Determine the Farm Classification Systems of Bali Pigs. Int. J. Sci. Res. 6(10): 1602-1606.

Sanjaya IGAM. 2013. Efektifitas Penerapan Simantri dan Pengaruhnya terhadap Peningkatan Pendapatan Petani-Peternak di Bali. (disertasi). Denpasar: Universitas Udayana, Program Pascasarjana.

Sanjaya D, Haryanto A, Tamrin. 2015. Produksi biogas dari campuran kotoran sapi dengan kotoran ayam. J Teknik Pertanian Lampung. 4(2): 127-136.

Soehadji. 1992. Kebijaksanaan Pemerintah Dalam Pengembangan Industri Peternakan dan Penanganan Limbah Peternakan. Direktorat Jendral Peternakan Dapertemen Pertanian. Jakarta.

Sudita IDN, Mahardika IG, Suarna IW, Partama IBG. 2015. Analysis of Feed for Digestbility Bali Cow in Group Simantri Programing Bali on Different Topigraphic. Int. J. Adv. Sci. Eng. Info. Thec. 5(6): 495-500.

Suwiti NK, Besung INK, Mahardika GN. 2017. Factors influencing growth hormone levels of Bali cattle in Bali, Nusa Penida, and Sumbawa Islands, Indonesia. Vet. World. 10(10): 12501254.

Warsana. 2009. Pemantapan Kelembagaan pada Gapoktan. BPTP Jawa Tengah. 